\title{
Más allá de lo real y la ficción. La imagen y la palabra en Bajo este sol tremendo, de Carlos Busqued.
}

\section{Resumen}

En Bajo este sol tremendo, de Carlos Busqued (2009), lo primero que se nota es que la narrativa ficcional está construida con diversas referencias a los medios, principalmente a los documentales televisivos exhibidos en Discovery e History Channel. Y no sólo los temas, sino que los recursos audiovisuales de estos programas también son transferidos a la forma verbal, haciendo que la narrativa sea exhibida con recursos del formato televisivo. La construcción de la propia visualidad del texto al relacionarse con la proliferación de imágenes exteriores que también tienen espacio en la novela es la fórmula que juega con nuevos regímenes de lo sensible y del sentido que necesita ser analizada. El objetivo de este trabajo es, por lo tanto, realizar el análisis de la relación entre la imagen y la palabra en la obra de Busqued, que disuelve las fronteras de los campos del arte y los massmedia, para apropiarse de sus lugares, herramientas y poderes.

Palabras claves

Imagen, documental, post-autonomía, real, ficción

\begin{abstract}
In Bajo este sol tremendo, by Carlos Busqued (2009), the first thing to note is that the fictional narrative is built with references to the media, mainly television documentaries exhibited in Discovery and History Channel. And not just the topics but audiovisual resources of these programs are also transferred to the verbal form, causing the narrative to be displayed with resources from television format. The construction of the visual text to interact with the proliferation of images which also have space in the novel is the formula that plays with new regimes of the sensible and the direction that needs to be analyzed. The aim of this paper is, therefore, the analysis of the association between the image and the word in the work of Carlos Busqued, which dissolves the confines of the fields of art and the mass media, to seize their places, tools and sway.
\end{abstract}

Keywords

Image, documentary, post-autonomy, real, fiction 


\section{Introducción}

Aunque ya se grababan algunos planos secuenciales en el final del siglo XIX con el objetivo de documentar rutinas de la producción industrial, hábitos de animales y otros registros científicos, "Nanook el esquimal", grabado por Robert Flaherty en 1922, es considerado por muchos como la primera película documental de la historia, por incorporar procedimientos de ficción en la documentación de un hecho real. "Por primera vez se articuló una historia de 79 minutos con escenas de la vida real que generaba emociones en los espectadores, ya que antes sólo se exhibía tomadas cortas que mostraban acciones sin una intención narrativa" (Chamucero, 09). Este empleo de técnicas ficcionales para intervenir en la realidad pasó a ser característica del documental, considerado un género híbrido, para aumentar el efecto de verosimilitud y captar la atención del espectador.

Entre 1985 y 1997 tres de los canales más conocidos mundialmente por ofrecer una programación específica de documentales fueron creados: Discovery Channel, History Channel y National Geographic. En esta época, la televisión ya había conquistado espacio en las salas de la mayoría de los hogares en América y Europa, además de un puesto permanente en restaurantes, salas de espera, hospitales, etc., tornándose uno de los objetos más presentes del siglo $\mathrm{XX}$, como afirma Jost (2012). Cuando el documental ganó espacio en la pequeña pantalla, el género recibió diversos ajustes para adaptarse a las necesidades del dispositivo. Se convirtió en un formato televisivo (Saló, 2013), es decir, un molde de programa que cambia su contenido dependiendo del tipo de público, hora de exhibición, país de transmisión, etc., pero sus características estructurales permanecen las mismas.

Algunas de esas características son: la voz in off, que se tornó el modo principal de narrar; la serialidad, es decir, la retórica de la repetición: los cortes en la narrativa para la exhibición de propagandas comerciales, que pasaron a hacer 
CATEDRAL Tomada: Revista de crítica literaria latinoamericana / Journal of Latin American Literary Criticism Más allá de lo real y la fic ción. La imagen y la palabra en Bajo este sol tremendo, de Carlos Busqued.

que cada bloque tuviera que retomar el problema y el tema puesto en el bloque anterior; además de remitir también a una serie (producción continua) de programas con el mismo tema pero de puntos de vista o abordajes distintos; y la inserción de entrevistas, simulaciones, relatos de especialistas, diarios de campo, sumados a otros materiales audiovisuales, etc.

Empiezo este trabajo con una serie de preguntas aunque la intención no sea encontrar respuestas finales, sino proponer una discusión, exponer un nuevo modo de leer esta y otras narrativas del presente y quizás, solo tenga la oportunidad de generar más dudas sobre la función, el efecto y la lógica de la imagen televisiva cuando se articula con la visualidad construida en el texto. En este sentido, las primeras preguntas que propongo, retomando a Cóccaro, son las siguientes:

Cómo "contar" la imagen, cómo escribir la imagen, cómo darle lugar a la renovación que opera en el lenguaje; qué relación hay entre la imagen y la palabra [...], cuándo la palabra se convierte en imagen, cuándo es más imagen que palabra, cómo existe la imagen fuera de la palabra, cómo la palabra puede salirse de la palabra. (Cóccaro, 245)

\section{La expansión de la palabra}

Articulando los elementos del formato del documental ya relacionados con la narrativa literaria - pensando no en el concepto de influencia sino de traducción de procedimientos y apropiación de determinados materiales - la obra que analizaré, Bajo este sol tremendo (2009), publicada por la editorial Anagrama, trae al texto estos recursos retirados del documental televisivo, además de imágenes y reportajes tomadas de revistas y diarios, para expandir no sólo la discusión de la posautonomía conquistada (Ludmer), sino también el carácter inespecífico del arte del siglo XXI, calificación dada por Florencia Garramuño en 
Frutos estranhos. Según la autora, muchos artistas latinoamericanos del presente están apostando por un arte que se declara y se define como una unidad de exploración creativa, que disuelve fronteras para manipular recursos y materiales de la historia, de la política, del mercado etc. que también la constituye; que redescubre sus formas, liberadas de cualquier rigidez de determinación exterior o interior, para traer al texto nuevas funciones, afectos, efectos, memorias y otras significaciones, sin pretensión alguna de pintar una realidad totalizadora.

Según mi lectura, la obra de Carlos Busqued reivindica esta condición expandida. Y el objetivo de este texto es analizar cómo se construye esta visualidad del texto al relacionarse con la proliferación de materiales preexistentes - imágenes exteriores fabricadas en la televisión, revistas, diarios etc. - puestos en el interior del texto, y preguntar qué hacen esos elementos en la tensión de lo real y la ficción. La hipótesis es que al atravesar diversos soportes y traerlos cargando información al texto literario, es posible deconstruir las jerarquías entre autor y lector, entre acción y contemplación, para generar una "comunidad anticipada de narradores y de traductores" (Rancière, Espectador 27). Ese común compartido, que dice también Garramuño ser la llave del arte contemporáneo, que liga "lo que se sabe con lo que se ignora" (27) y reconfigura lo sensible, fractura lo real, entrelaza los varios regímenes de expresión, y opera esos ajustes justamente para producir imágenes que se articulan con otras lógicas de pensamiento.

\section{Bajo el sol la imagen}

El primer párrafo de la novela empieza con un audio: es la voz del narrador de un documental de Discovery Channel sobre la caza nocturna del calamar Humboldt, visto por el personaje Cetarti en la televisión de su casa, en Córdoba. El segundo párrafo esclarece: la televisión está casi sin sonido, así que no es el 
CATEDRAL TOMADA: Revista de crítica literaria latinoamericana / Journal of Latin American Literary Criticism Más allá de lo real y la fic ción. La imagen y la palabra en Bajo este sol tremendo, de Carlos Busqued.

audio original lo que "oímos" - un especialista hablando en inglés -, sino los subtítulos en castellano. Las informaciones sobre el calamar son muy precisas. En menos de un minuto, el narrador del documental ya revela al espectador sobre la naturaleza violenta del Humboldt, sus hábitos alimenticios (y caníbales), y la forma violenta también de cómo capturarlo. Con el uso de la letra cursiva, ese tipo de desplazamiento de un material de otro medio a la obra literaria ocurre con frecuencia en toda la narrativa. Sólo en el primer capítulo se suman tres recurrencias. Pero más que eso: el documental televisivo en la novela de Busqued supera la tematización para ser incorporado también como formato, en el nivel estructural y sintáctico, es decir, su técnica y narrativa.

La novela, tal como un documental, es narrada por una voz in off, esa voz que muestra y cuenta creando una unidad entre las imágenes y la historia. De esa manera, el narrador es quien elige la cámara y el punto de vista que más interesa a cada escenario y escena, y que cumple su intención narrativa. Así el narrador muestra y cuenta la trama de los personajes, privilegiando no sólo algunos datos determinados (como por ejemplo, los hábitos alimenticios, sus actividades nocturnas, reacciones delante de un animal, conductas frente a un evento violento), sino también el punto de vista de dos de los personajes, para que el lector detenga su mirada, acompañándoles, como si la cámara estuviera en su hombro. El foco de la cámara se intercala entre la descripción de la vida que llevan Cetarti y Danielito, dos tipos que parecen animales fuera de su tiempo y hábitat natural.

Cetarti y Daniel tienen edad parecida (alrededor de los cuarenta años), pero actúan como niños en muchas escenas. Danielito, que desde su apodo se muestra infantil, a pesar de su gran tamaño, todavía se orina en la cama. Cetarti se marea y tiene ganas de vomitar cuando ve escenas sexuales o una simple caja de preservativos. No son hombres violentos, parece que en realidad no crecieron, no se desarrollaron, y por eso mantienen una mirada ingenua, como si fueran animales en la etapa larval. Nada los forzó a desarrollarse, "como un renacuajo que vive su vida entera sin convertirse en rana" (Busqued, 92), o una larva de 
salamandra, el ajolote que Cetarti mantiene en una pecera y que pasa tanto tiempo observándola. El narrador no sólo los identifica con los mismos verbos y adjetivos sino que, a veces, los invierte la posición de observador. Es el ajolote quien observa Daniel y Cetarti, los observados. Y éste no es el único animal con el que los personajes se obsesionan y pasan horas entretenidos: un escarabajo venenoso también es mantenido en una pecera para que los personajes admiren sus movimientos. "Y cuando el ratón se terminó de morir, el bicho como que se despertó y se lo comió entero. Tardó un día y medio en comérselo, no paraba. Dejó los huesitos limpios. Cetarti se imaginó las caras de Duarte y el tal Danielito observando la escena a través del vidrio de la pecera". (165).

Así como el lector, Cetarti y Daniel permanecen a una distancia segura de la violencia: el contacto es sólo visual, por la tele, por la pecera... Aún cuando son cómplices de los secuestros que hace Duarte, su trabajo es darles comida a los secuestrados o acompañarles. Es decir, delante de una realidad hostil, llena de creaturas feroces, desde Duarte el secuestrador a una lampalagua gigante capaz de comer un chancho, las imágenes que ven Cetarti y Daniel en programas televisivos están en una distancia intransitable, y la violencia controlada parece hacer de la sala/la realidad donde están en un lugar seguro. Las acciones de violencia real, como la violación de la señora secuestrada por Duarte o la confrontación entre la madre de Daniel y su perro, son escenas casi siempre invisibles por estos dos personajes. Son contadas de un personaje a otro, o llegan a Cetarti y Daniel a través de otros sentidos: sonidos u olores.

En sus casas, sus burbujas de aire, ellos están protegidos, ya que la violencia es admitida, pero está organizada y normalizada en la pantalla, en la revista, en el diario. La televisión aparentemente da cuenta de lo real, porque lo clasifica (como un archivo). En la pantalla el tiempo es el presente permanente, una eterna repetición, donde la realidad y la ficción se mezclan, y los tiempos pasado o futuro están suspendidos simultáneamente. Así un caso internacional como el de los elefantes asesinos en India se articula con un evento local, el del elefante en Córdoba que fue torturado con chapas eléctricas, ya que la televisión permite esas 
CATEDRAL TOMADA: Revista de crítica literaria latinoamericana / Journal of Latin American Literary Criticism Más allá de lo real y la fic ción. La imagen y la palabra en Bajo este sol tremendo, de Carlos Busqued.

conexiones de espacio-tiempo y capacita al espectador para hacer lo mismo, mezclando informaciones y conocimientos del mundo real con otras historias. Por eso, el narrador explica que cuando Cetarti imagina cómo era la vida de su hermano la ve tan real como las imágenes del mítico Pie Grande (141). Con el tiempo histórico suprimido y la exhibición de documentales episódicos no lineales y sus repeticiones, no hay una noción de temporalidad, una necesidad de registrar en el tiempo la sucesión de hechos. De esa manera, cuando los personajes están delante de la muerte de sus familiares, no hay duelo ni tampoco conexión y ordenación de los eventos. Cetarti y Daniel son hijos de una generación que creció viendo la tele, y una proliferación de imágenes y sonidos que necesitan para ocupar el vacío de sus vidas. Tanto es así que no hay prácticamente ninguna escena en que la televisión o la radio no estén encendidas. Los medios ocupan un silencio, que persiste.

\section{El silencio de los cabos sueltos}

Hay en el libro varias preguntas no contestadas. Cabos sueltos, o más bien, pistas que los personajes no conectan. Dos de esas preguntas corresponden al hermano de Cetarti. Primero, cuando Cetarti revisa los objetos personales del hermano muerto, encuentra su documento de la policía federal. Ese dato de que su hermano era policía parece no interesarle, pero ¿por qué será que Molina, el oficial retirado y casado con su madre, lo asesina? Hay otro dato que no se termina de descifrar: la casa donde vivía en Córdoba no tiene escritura. Nadie se pregunta por qué esas casas y las otras de su barrio no tienen escritura. El narrador no brinda más información, porque los personajes parecen no leerlas en el contexto, como si las preguntas murieran junto con sus muertos.

Según Derrida (2007), la ley siempre está por venir, vive en el vacío, suspendida, y por tanto no puede ser vista porque su presencia se escapa. La ley 
es futura, prometida, y sólo existe en el presente en un acto performativo, o sea, después que la violencia que la rellena ocurre. Es decir, la violencia está antes y delante de la ley, ya que la ley depende de la presencia de la violencia para legitimarse. Cuando la ley aún no se hace presente, el tiempo anterior es el de la violencia fundadora. El tiempo posterior de la justicia, que es la acción bien sucedida del Estado, tiene una función importante para el instante que lo funda: legitima la violencia que lo produjo y se "alimenta", se "sirve" de ella, para reafirmarse, produciendo así un círculo hermenéutico, visto que es la violencia que conserva el derecho.

En el libro de Busqued este círculo está muy presente. La violencia controlada, que es el discurso del Estado, solo aparece en la televisión. Luego, si en la realidad, la ley no pune y por ende no tiene presencia, la violencia también continúa instaurada (esperando el momento de la justicia). Mientras las atrocidades del pasado y del presente no sean resueltas, la sociedad queda en ese tiempo suspenso, agarrándose de la seguridad que tienen en las imágenes vistas en la pantalla. Sin Estado que lo castigue, lo inadmisible ocurre. De ahí que la escena donde Daniel muele los huesos de su hermano muerto y los echa en el inodoro junto con las cenizas de su madre, después que entierra sus perros en el jardín, parece estar tan fuera de sentido. La narración de esas imágenes aumenta el potencial de realidad del documental con el que el narrador construye en el texto. Con un discurso que legitima la violencia del acto de Daniel, Duarte se apropia incluso del argumento biopolítico (Foucault) de que la violencia es necesaria para reponer la salud en su posición normativa y dice: "Hiciste bien [...] Si los hubiera enterrado o hubieras guardado las cenizas, iban a estar ahí para siempre. Es muy sano, me parece. Se fueron, ya no están más”. (Busqued, 156). 
CATEDRAL Tomada: Revista de crítica literaria latinoamericana / Journal of Latin American Literary Criticism Más allá de lo real y la fic ción. La imagen y la palabra en Bajo este sol tremendo, de Carlos Busqued.

\section{Las fotografías narrativas}

Con la apropiación de los procedimientos del formato documental (montaje, timing, repetición, serialidad) que al final ya parecen ser elementos naturales de la obra literaria, el narrador, además, libera algunas imágenes "reales", sacadas directamente de revistas y diarios encontrados por los personajes. Esa relación entre lo real y la ficción se tensiona porque el texto ya crea su propia visualidad, es decir, imágenes mentales resididas en el "poder imaginativo de la palabra". Pero éstas se relacionan con una proliferación de imágenes exteriores, fabricadas en otros medios y que también son presentadas en el texto. Estas imágenes que no sabemos bien si "son naturales o artificiales, simuladas o reales" (Laddaga, 14), "não servem para ilustrar o texto, mas ao contrário, criam uma tensão que corrói os recursos narrativos convencionais e a relação equilibrada entre a história e a imagem" (Schøllhammer, 141). O sea, incluyen una sombra de la realidad al incluir otros soportes de imágenes.

Dos de las imágenes puestas en el libro, por ejemplo, el narrador dice son recortadas de la revista Muy Interesante, y están acompañadas de una frase - un subtítulo - que las explica: 'Las páginas que pegó Cetarti en la pared de la cocina" (Busqued, 98-99). Esa operación de texto-imagen-texto implica una serie de cuestiones hacia los límites de la tensión entre realidad, simulacro, representación, ficción: ¿qué es real? ¿Sólo porque se dice que esas páginas fueron retiradas de una revista ésas imágenes son más reales que las construidas en la visualidad del texto literario? ¿Qué garantiza que esas imágenes no fueron editadas o creadas en una computadora? ¿Qué legitiman esas y no otras? Tensionar la idea de realidad ya es fracturarla, ya es provocar nuevas percepciones en el lector, y es eso que Rancière dice que es el trabajo del arte contemporáneo: hacer que el artista y el espectador indaguen su mirada la propia realidad que, según el autor, no deja de ser una ficción más: 'Lo real es siempre el objeto de una ficción, es decir, de una construcción del espacio en el que se 
anudan lo visible, lo decible y lo factible. Es la ficción dominante, la ficción consensual" (Rancière, Espectador 78).

Hay aún otros tipos de imágenes recortadas en el texto. Son fotos casi siempre violentas que los personajes encuentran y que son descritas bajo su punto de vista, pero que por la naturaleza inmadura de los personajes, Cetarti y Daniel, son descritas desde una óptica ingenua. Las primeras que surgen son las fotos de la escena del asesinato del hermano y de la madre de Cetarti, seguidos del suicidio de Molina: 'La cabeza del tal Molina era un desastre (vista al revés parecía una bolsa desfondada), pero las caras de su madre y su hermano estaban intactas y los dos con el mismo gesto de estar mirando fijamente algo no demasiado entretenido" (Busqued, 16). En otra escena, Daniel encuentra una secuencia de fotos y las analiza. Son casi todas fotos de operativos rurales y equipamientos de la fuerza aérea cuando su padre, Molina, aún era militar. Nuevamente, el lector se encuentra con imágenes violentas, pero observadas desde el punto de vista infantil:

De fondo se veía una camioneta cosida a balazos. Entre el guardabarros y el comienzo de la caja, que era la porción que se veía, Danielito contó nueve agujeros de un calibre muy grueso. Su padre estaba de cuclillas, descansando sobre la rodilla el brazo derecho con la pistola [...]. A su lado tres personas acostadas, cuyas caras habían sido tapadas con líquido corrector. (150)

En su lectura de las fotos no hay imágenes de violencia. Daniel lee en ellas su transparencia ilusoria. Sin subtítulos, contexto o memoria, para él, su padre descansaba y las personas son descritas como si estuvieran acostadas, y no muertas. Daniel no problematiza sus ausencias y no interroga sus particularidades, algo que sólo la fotografía consigue salvar del tiempo y del espacio pasado. Él no sabe leer lo que las imágenes "están diciendo" (Sontag, 2003). Pero también ahí hay muchos vacíos. ¿Quiénes son esas personas muertas y qué hicieron? ¿Qué 
CATEDRAL TOMADA: Revista de crítica literaria latinoamericana / Journal of Latin American Literary Criticism Más allá de lo real y la fic ción. La imagen y la palabra en Bajo este sol tremendo, de Carlos Busqued.

hizo Molina y por qué? En la novela, Daniel "puso las fotos en su lugar y las devolvió al estante. Se quería ir." (Busqued, 151). Pero esos enigmas de la imagen que instiga el lector a abrir los archivos (Didi-Huberman, 124), a buscar otras pistas en el libro, para intentar - en vano- organizar la historia, rellenar las lagunas, es lo que comparte el narrador con el lector: un común fragmentado, que ni el lenguaje ni las imágenes dan cuenta de representar en su totalidad. Ese deseo de intercambiar lugares y diluir poderes entre autor y lector, y reedificar el espacio público (Rancière, Espectador 27) es algo que la novela de Busqued consigue instaurar y que es el rasgo fundamental del arte contemporáneo.

\section{Un archivo entre lo real y la ficción}

La literatura al absorber omnívoramente (Garramuño) esos índices de lo real, es decir, al fagocitar lenguajes, soportes y restos de la realidad en su práctica artística, abre un archivo: las fotografías, las imágenes de la pantalla, de la revista, los registros de noticieros, otros audios, más la construcción de la propia visualidad del texto, erige su fórmula que juega con los nuevos regímenes de lo sensible y del sentido, y que disuelve identidades de los campos del arte, de la historia, la política, de los massmedia, para apropiarse de sus herramientas y funciones. Un archivo, como dice Derrida, que no es una cuestión del pasado, sino una cuestión de futuro: "Trata-se do futuro, a própria questão do futuro, a questão de uma resposta, de uma promessa e uma responsabilidade para amanhã. O arquivo, se queremos saber o que isto teria querido dizer, nós só o saberemos num tempo por vir." (Mal de arquivo 50-51). El archivo de lo real que elabora el arte hoy:

Establece que somos diferencia, que nuestra razón es la diferencia de los discursos, nuestra historia la diferencia de los tiempos, nuestro yo la 
diferencia de las máscaras. Que la diferencia, lejos de ser origen olvidado y recubierto, es esa dispersión que somos y que hacemos. (Foucault, 223).

Con la televisión, la internet y las nuevas tecnologías, la estimulación del intercambio cultural ha crecido exponencialmente, y por eso, dice Rancière que el arte es hoy el lugar donde artistas y espectadores, "participantes activos en lugar de ser voyeurs pasivos" (Rancière, Espectador 11), hacen que las nuevas formas de "circulación de la palabra, de exposición de lo visible y de producción de los afectos" (67) sean compartidas. Si la literatura nunca fue tan parecida con la realidad como hoy será también porque lo real nunca se utilizó tanto también en la ficción para su composición, y es ese estado de constante disputa que también se ubica la obra de Busqued.

\section{Bibliografía}

Busqued, Carlos. Bajo este sol tremendo. Barcelona: Anagrama, 2009.

Chamucero, Daniel. El documental como formato televisivo. Bogotá: Pontificia Universidad Javeriana, 2010.

Cóccaro, Victoria. "Acercamientos teóricos al problema de la percepción y escritura de imágenes: el montaje como procedimiento". Revista Escritura e Imagem. Vol. 9. (2013): 237-251.

Derrida, Jacques. Força de lei: o fundamento místico da autoridade. São Paulo: Martins Fontes, 2007.

---. Mal de arquivo: uma impressão freudiana. Rio de Janeiro: Relume Dumará, 2001. 
CATEDRAL Tomada: Revista de crítica literaria latinoamericana / Journal of Latin American Literary Criticism Más allá de lo real y la fic ción. La imagen y la palabra en Bajo este sol tremendo, de Carlos Busqued.

Didi-Huberman, Georges. "Cascas" Revista Serrote. n.13. São Paulo: Instituto Moreira Salles. (2013): 98-133.

Foucault, Michel. La arqueología del saber. Buenos Aires: Siglo XXI, Editores Argentina, 2005.

Garramuño, Florencia. Frutos estranhos. Sobre a inespecificidade na Estética Contemporânea. Rio de Janeiro: Rocco, 2014.

Gatzemeier, Claudia. "Hacia una estética de la marginalidad. Entre la nueva novela negra y el realismo sucio: Retrato de familia con muerta de Raúl Argemí y Bajo este sol tremendo de Carlos Busqued”. Diseño de nuevas geografías en la novela y el cine negros de Argentina y Chile. (ant.) Frankfurt/Madrid: Iberoamericana Editorial Vervuert/ Ediciones de Iberoamericana. (2013): 193-207.

Giorgi, Gabriel. Formas comunes. Animalidad, cultura y biopolítica. Buenos Aires: Eterna cadencia, 2014.

Jost, François. El culto de lo banal. Buenos Aires: Libraría Ediciones, 2012.

Laddaga, Reinaldo. Espectáculos de realidad. Rosario: Beatriz Viterbo, 2007.

Ludmer, Josefina. "Literaturas postautónomas: Otro estado de la escritura". 2012. Web: Acceso: 11/11/2015

Rancière, Jacques. A partilha do sensível. São Paulo: Editora 34, 2009.

---. El espectador emancipado. Pontevedra: Ellago Ensayo, 2010.

Saló, Gloria. ¿Qué es esto del formato? Barcelona: Gedisa, 2013.

Schollhammer, Karl Erik. "Realismo afetivo: evocar realismo além da representação". Estudos de literatura brasileira contemporânea. n.39. (2012): 129-148. 2012. Web. 11 noviembre 2015.

Sontag, Susan. Diante da dor dos outros. São Paulo: Companhia das letras, 2003.

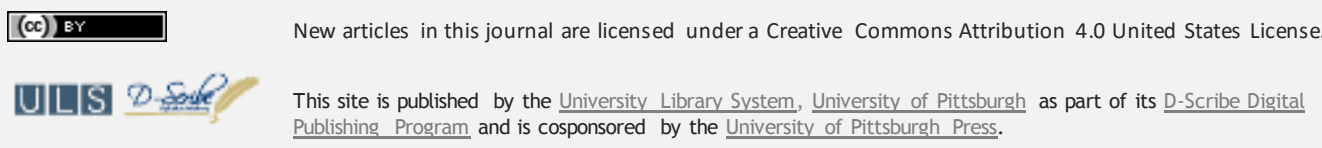

